\title{
Maternal Fetal Conflict from Legal Point of View Comparing Health Law in the United States and Islamic Law
}

\author{
Rahma Aburas $^{1 *}$, Mary Devereaux ${ }^{2,3}$ \\ ${ }^{1}$ Master Program in Health Policy and Law, Department of Anesthesiology, School of Medicine, University of California (San \\ Diego), San Diego, USA \\ ${ }^{2}$ Rady Children's Hospital, San Diego, USA \\ ${ }^{3}$ Department of Pathology, Faculty Affiliate, Philosophy, University of California, San Diego, USA \\ Email: ^raburas.aa@gmail.com
}

How to cite this paper: Aburas, R. and Devereaux, M. (2017) Maternal Fetal Conflict from Legal Point of View Comparing Health Law in the United States and Islamic Law. Open Journal of Obstetrics and Gynecology, 7, 791-799.

https://doi.org/10.4236/ojog.2017.78080

Received: May 2, 2017

Accepted: July 30, 2017

Published: August 2, 2017

Copyright $\odot 2017$ by authors and Scientific Research Publishing Inc. This work is licensed under the Creative Commons Attribution International License (CC BY 4.0).

http://creativecommons.org/licenses/by/4.0/

\begin{abstract}
Objectives and Methodology: The purpose of this paper is to demonstrate how maternal and fetal interests can sometimes be conflicting, and a situation can place care providers in a difficult position when it comes to decisionmaking. The study also intends to cover the health laws that deal with such situations in the legal systems of the United States and Islamic Law. This study takes the form of a critical literature review. The literature search was conducted using electronic citation databases that included Pub Med, Medline, Google Scholar, and others. The keywords used in this research related to medical and legal terms concerned with fetal rights, such as embryo, fetus, abortion, fetal rights, health law in the United States, Islamic health law, and comparative studies. The search was conducted in English as well as Arabic. Data were collected from books, journals, government documents, and Internet websites. Results: Doctors sometimes have to make difficult decisions when caring for pregnant women, since one person's care directly affects another's. The fetus depends fully on its mother for survival in the uterus. Nevertheless, at times it so happens that the interests of the mother and fetus differ. In such cases, a conflict between the two arises. Due to advances in technology in the medical field, doctors can now specifically target the fetus during medical procedures. When treating two different patients, health practitioners must choose that which is best for each patient independently. Approach to the maternal-fetal conflict must consider medical concerns, as well as legal ones. While there is some consistency in the medical approach between different countries, the legal part varies considerably, even among different states in America, as fetal legal status, personhood, and rights differ greatly. Islamic Law is practiced in many countries and has a special consideration for the fe-
\end{abstract}


tus that is worth attention and understanding. Conclusion: Medically, when the interests of the mother and the fetus are in opposition, a maternal-fetal conflict arises. The two main forms are harmful maternal behavior to the fetus and maternal refusal to undergo specific procedures to improve the health condition of the fetus. Different states in the US have different health laws to deal with some aspects of maternal fetal conflicts, but on many occasions, no explicit rules can be found and healthcare workers need to use their own judgment. In Islamic Law, both conditions (i.e., harmful maternal behavior or refusal to employ lifesaving procedures for the fetus) follow the general jurisprudence rule (damage needs to be removed), and the mother will be legally accountable if her actions result in fetal damage or death.

\section{Keywords}

Maternal-Fetal Conflict

\section{Introduction}

Maternal-fetal conflict occurs when the interest of the mother is incompatible with the rights or interest of her fetus. With modern technology, physicians can monitor the fetus closely to ascertain its exact condition, and know if there is any intervention that could promote fetal health and wellbeing. These interventions will act towards the fetal interests, but not necessarily act towards the mother's interest, since some interventions will expose the mother to some tests or surgical procedures that she does not like [1].

Maternal-fetal conflict could arise electively through the mother's choice to terminate her pregnancy, or to practice any kind of harmful behavior, such as substance abuse that affects her fetus adversely. Another form of conflict could arise in the case of medical conditions, when either the mother or the fetus requires medical intervention that brings harm or side effects to the other party, for example, performing a cesarean section for fetal distress, or treatment of maternal cancer during pregnancy that could result in fetal death. In many cases, doctors must make difficult decisions, since one person's care directly affects the other's in such cases; in such, a conflict between the two arises [2]. The relationship between the mother and the fetus is no longer medically perceived to be of cohesion but rather of duality. When treating two different patients, health practitioners must choose that which is best for every patient independently [3]. This is, however, problematic in a maternal-fetus case due to the fetus's dependence on its mother. This dependence usually leads to conflict between the rights of the mother and those of the fetus. Fetal diagnosis and treatment have experienced advancements, which have enhanced fetal outcome. Nonetheless, all fetal diagnosis and treatment administered to improve fetal outcome must take into consideration the wellbeing of the mother. Usually, the mother agrees to whatever intervention is best for her child. Still, cases do exist whereby the mother does not [4].

The primary type of conflict between mother and fetus arises when the moth- 
er's conduct and actions pose harm to the fetus (for example, if the mother participates in activities when pregnant such as alcohol abuse, smoking or using illegal drugs). The other type of conflict between mother and fetus occurs when "the mother may reject diagnostic procedures, medical treatment, or a surgical operation intended to upgrade or maintain fetal wellbeing" [2]. Cases of maternal refusal could include declining advised bed rest, amniocentesis for purposes of diagnosis, corticosteroids that enhance lung maturity in the fetus or tocolytics that prevent premature birth. Although the majority of pregnant women readily accept risking their own health to enhance the fetal outcome, sometimes, some women do refuse treatment encouraged for the fetus. When a woman refuses to undergo medical therapy that could save the life of her fetus, complex ethical issues arise [3].

\section{Objective and Methodology}

This paper aimed to highlight an impotent obstetrical medical issue which is maternal fetal conflict, but from a different perspective; from the legal point of view. It also intended to compare the approach of this issue between the health law in the United States and the Islamic health law.

This study is designed in the form of a critical literature review. Literatures were searched by conducted by using electronic citation databases like Pub Med, Medline, Google scholar and some others. The key words used are related to medical and legal terms concerned with maternal-fetal conflict, such as fetus, abortion, fetal rights, health law in the United States, and Islamic health law. The search was conducted in English as well as Arabic. Data were collected from books, journals, government documents and Internet websites. The comparative method followed in this project is the functional method [4], which is expressed either as case-to-case comparison or narrative of specific aspects of individual law, especially in conditions that are peculiar to one system.

\section{Results and Discussions}

\subsection{Maternal-Fetal Conflict in the United States}

Under the Constitution of the US, legal rights are focused on the expectant woman. She has the right to decline medical procedures she deems undesirable, as well as a right to privacy, self-determination and bodily integrity. Despite these woman's rights, they may not be outright [2]. This is due to the fact that a pregnant woman's decisions and activities directly affect the fetus. Activities such as use of illicit drugs, consuming of excess alcohol, foregoing medical treatment, as well as refusing to follow the doctor's advice, can cause adverse effects to the fetus.

The dilemma on how society should deal with women who intentionally abuse drugs while pregnant has boggled lawmakers for almost three decades. Use of drugs, especially amphetamines and cocaine, during pregnancy is considered a criminal act in some states (see Figure 1). When caught, one is susceptible to being stripped of parental rights. There are few instances whereby women have 


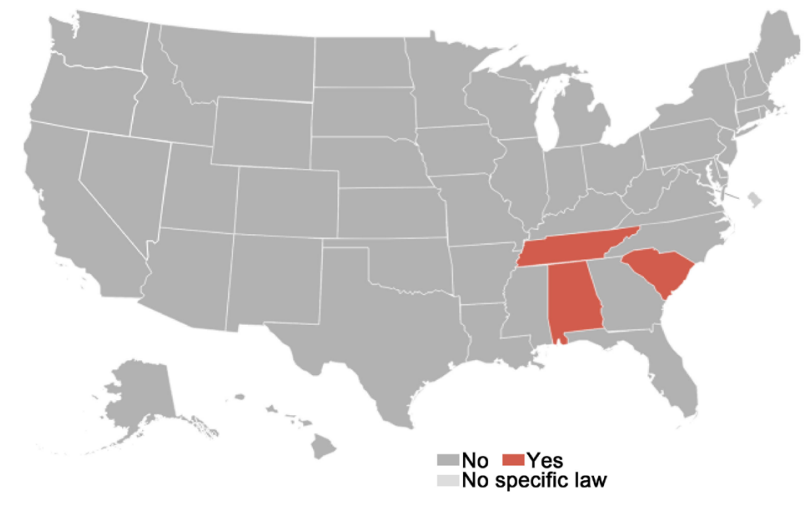

Substance abuse during pregnancy is a crime

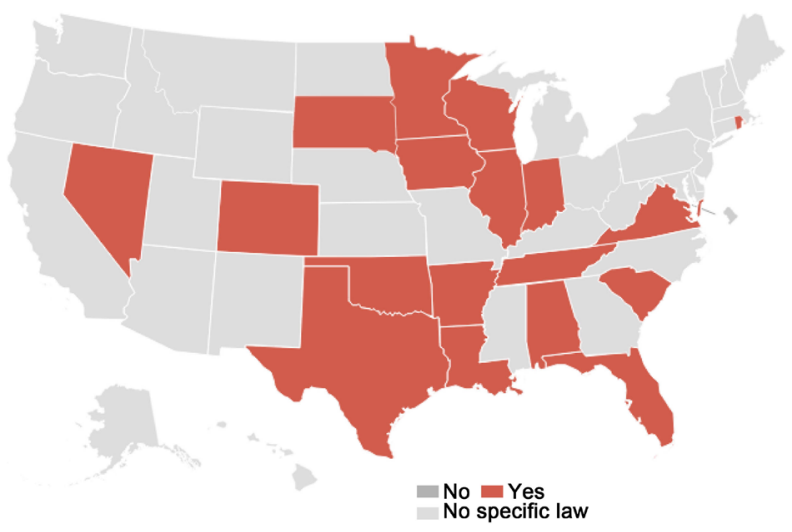

Substance abuse during pregnancy is child abuse

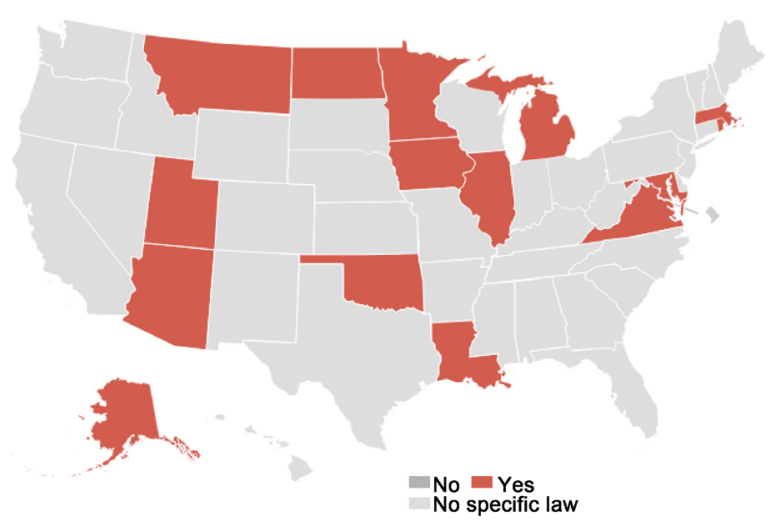

Health care workers must report drug abuse during pregnancy

Source: Miranda L., Dixon V. and Reyes C. (September, 30, 2015). How States Handle Drug Use during Pregnancy https://projects.propublica.org/graphics/maternity-drug-policies-by-state (With permission from ProPublica) [8].

Figure 1. How States handle drug use during pregnancy.

been indicted for harming their fetus. Nevertheless, the few attempts at imprisonment have been fruitless, since advocates for the reproductive rights of women oppose the regulations set by the state regarding the behavior of preg- 
nant women [2].

According to the $14^{\text {th }}$ Amendment, a fetus is not considered a person; however, the Supreme Court of the US has also stated that the state has a "stake in preserving the fetus' life after conception". Currently, 36 states recognize an unborn fetus as a viable victim in accordance to the Unborn Victims of Violence Act of 2004. According to this law, everything starting from the zygote to the fetus is regarded as an autonomous victim, with rights that are different and unique from those of the mother. In 2002, the US Department of Health and Human Services also added individuals existing in the period between conception and birth to the definition of the word "child" in the State Children's Health Insurance Program so as to ensure these individuals have insurance coverage [5].

One main example in the matter of women refusing medical treatment or surgical procedures that could adversely affect the fetus is the issue of agreeing to emergency cesarean section. This procedure could determine whether the fetus lives or dies. Performing such surgery without consent can be deemed as assault or battery [2]. Cesarean surgery is considered invasive and those who undergo it get scarred and sometimes experience emotional trauma.

In every three births that occur in the United States, one is delivered by a cesarean section [6]. Cesarean delivery is so popular nowadays that it is currently the most frequently performed surgery in American hospitals. A large number of the women who voluntarily undergo cesarean delivery do so to maximize the healthy outcome of their babies. Nevertheless, there are some women in the US who choose to decline cesarean delivery, regardless of their physician's recommendations. Many reasons exist as to why women opt to decline a doctor-recommended cesarean section. These reasons include worry or fear regarding postoperative pain, fetal harm, and maternal and fetal death, operation and recovery fee, desire to keep away from future cesarean deliveries, cultural and religious beliefs, as well not understanding the importance of the procedure [6].

Although an obstetrician may decide to get a physician's court order, the option is time-consuming and this delay could lead to an increase in the risk of fetal death. Also, the process of legally getting a court order risks irreversibly damages the relationship between patient and physician [2]. According to the law, doctors are not required to seek intervention from the court regarding a pregnant patient. This could be intervention regarding behavior change or treatment for the good of the fetus. In addition, doctors are not liable in cases where their patients knowingly put their fetus in harm's way. However, a doctor that performs surgery without the woman's permission can be prosecuted [6].

The American Academy of Pediatrics Committee on Bioethics has outlined recommendations for physicians when the mother's and fetus' interests are not aligned. "Whereby treatment is liable to pose a risk to the mother or her right to bodily integrity, a doctor should do as the woman chooses. It is only under the following circumstances that the doctor should question the woman's decision: 1) the fetus is susceptible to irrevocable harm if treatment is not administered; 2) 
the treatment is indicated properly and is likely to work; and 3) there is minimal risk to the mother. If the woman still refuses, the doctor should present the matter to the hospital's ethics committee and only petition the courts as a last option" [2].

The American Congress of Obstetricians and Gynecologists (ACOG) Committee on Ethics in its policy statement advises that physicians should try to educate and give counsel to their patients in cases where "a mother declines a diagnostic procedure or surgery, thereby endangering her fetus, or in a case whereby the lifestyle or health practices of the mother pose a danger to fetus". ACOG states that counseling and educating are the best methods of getting a woman to heed the doctor's advice. In addition, ACOG "condemns coercing of pregnant women, since it threatens the relationship between physician and patient, as well as violates the purpose of the informed consent procedure" [7]. The Committee advises that in case of, "continued disagreement with the woman, the doctor should present the issue to the ethics committee. Involving the judicial system is rarely justified" [2].

Lastly, the American Medical Association discourages health practitioners from intervening in such cases by using court orders. "Doctors should keep from using the judiciary to impose their personal judgments on their pregnant patients who refuse medical advice that is meant to benefit their fetuses". However, if there is an exceptional circumstance whereby medical treatment that is to be administered does not pose significant or any health risk to said woman and does not entail many invasions to the integrity of her body and would definitely prevent harm to the fetus that is substantial and irreversible, then it would be appropriate if the physician seeks intervention from the court [5].

\subsection{Maternal Fetal Conflict in Islamic Law}

Islamic Law, or "Shariah", derived from the Qur'an and Prophet Mohammad traditions of "Sunnah", forms the basis of the legal system in some Muslim countries, e.g. Saudi Arabia. Shariah governs and regulates all aspects of a Muslim's public and private life.

There are four independent schools of thought regarding Shariah: Maliki, Hanafi, Shafei, and Hanbalī [9]. The four schools are considered to be equally valid for interpretation of the Shariahlaw. These schools have great agreement on all fundamental aspects of the religion. They all recognize the authority of the Holy Qur'an and the Sunnah as the ultimate source of Islamic law. However, in situations where neither source has clear text, the four schools use their objective reasoning, which may differ from each other [10]. Although Saudi law uses the interpretation of the Hanbalischool, on occasion, the doctrine of other schools of Islamic thought has been applied by Saudi courts where they found that approach to be appropriate in the interests of justice and fairness. The non-revealed sources of Shariah are founded in juristic reasoning (ijtihād). The juristic reasoning is done through analogy (qiyās), in the public interest. The subject of public inter- 
est (maslaha) is a valid source of Islamic law in areas where the Holy Qur'an and the Sunnah are not explicit [10].

Although the fetus is regarded as a person from the time of ensoulment, the right of the mother takes priority over the fetal right. However, in Islam, the mother has the responsibility to ensure the stability of the embryo or fetus, and she is expected to do whatever is needed to ensure the wellbeing of her fetus. During the month of Ramadan, when people are required to fast from daybreak to sunset, a pregnant woman is permitted to break her fast during the day if she fears that fasting might harm her fetus [11].

On the other hand, the mother is prohibited from any actions or negligence that might adversely affect her fetus; this includes consumption of drugs, alcohol, or smoking. She is also forbidden to take any action that could induce abortion, such as introducing an object into her uterus or taking certain medications to abort. "And do not kill the soul which Allah has forbidden, except by right" (Quran, 17:33) [12].

If a woman takes any action that could harm her fetus, she will bear sin and guilt, and if her action was a direct cause of her fetus' abortion and death after ensoulment, she will be held legally responsible for it. A question directed to the Permanent Committee for Scholarly Research and Advisory Opinion was answered as follows (Fatwa No. 19590):

"If the fetus, who was aborted after four months of pregnancy or more, it is regarded as a great sin, and she has to repent to God Almighty, and she has to pay the blood money to the heirs if requested, equal to freeing a slave or a nation, worth a tenth of women's blood money."

If the mother refuses to give consent for a procedure that could save the life of her fetus, such as refusing an emergency cesarean section, the attending physicians and caregivers will not be allowed to do it, no matter what will be the consequences. "No physician may perform a surgery for the patient without permission or authorization for whatever reasons, because the body of the patient from his jurisdiction is not entitled to others to act on it as it is not entitled to dispose of his property and discharge without his permission. Also, because the process of medical therapy and medication is the right of the patient and no one is allowed to assault him/her, this is the famous judgment among scholars, stipulated by Hanbali and Shafi'i and others" [13]. Another advisory opinion of senior scholars indicates that the authorization that counts for the cesarean section is the woman's permission and not her husband's, as stated in the Council of Senior Scholars in the Kingdom of Saudi Arabia Resolution No. (173) on 12/3/1993: "If it is decided medically by competent and trusted specialists that necessity requires surgery for a hysterectomy or ovarian removal or caesarean section, what accounts in this situation is the woman's authorization whether to do it or not. It does not require the consent of the husband or any other person; because the damage is related to her rather than others and she knows about herself" [14]. 
The mother is responsible for following the physician's advice to avoid damage to the fetus based on the jurisprudence rule (damage needs to be removed), and in order to maintain a religiously respectable life. If the mother does not do what is expected and follow the physician's advice, and her action results in the death of the fetus, she will be accountable legally; in this case, she faces the sentence of paying "Diya", i.e., blood fine, and atonement, which is fasting two months. Killing the fetus, intentionally or unintentionally, is penalized by the payment of $1 / 10$ of the mother's Diya, which is equivalent to 212.5 grams of gold or the price of five camels [15].

\section{Conclusion}

Mothers and fetuses usually share the same interests, but in some cases, the fetus requires medical interventions or actions from the mother that do not favor the mother, and this is where a maternal-fetal conflict arises. In the United States, specific rules apply to maternal harmful behavior to the fetus such as smoking, drugs or alcohol consumption, which differ from state to state. On the other hand, maternal refusal to undergo specific procedures such as emergency cesarean section requires extensive effort from the attending medical staff to convince the mother, but it usually does not require legal action. In Islamic Law, both conditions (i.e., maternal harmful behavior, or refusal of fetal lifesaving procedures) follow the general jurisprudence rule (damage needs to be removed), and if the maternal actions result in fetal damage or death, she will be considered sinful and will be accountable legally.

\section{References}

[1] Yeo, G.S. and Lim, M.L. (2011) Maternal and Fetal Best Interests in Day-to-Day Obstetrics. Annals of the Academy of Medicine, Singapore, 40, 43-47.

[2] Deshpande, N.A. and Oxford, C.M. (2012) Management of Pregnant Patients Who Refuse Medically Indicated Cesarean Delivery. Reviews in Obstetrics and Gynecology, 5, e144-e150.

[3] Ludwig, M. (1998) Maternal-Fetal Conflict: Ethical Topic in Medicine University of Washington School of Medicine. https://depts.washington.edu/bioethx/topics/

[4] Van Hoecke, M. (2015) Methodology of Comparative Legal Research. Law and Method, 1-35. https://doi.org/10.5553/rem/.000010

[5] Tran, L. (2004) Legal Rights and the Maternal-Fetal Conflict. Bio Teach Journal, 2, 77-81.

[6] Caughey, A.B., Cahill, A G., Guise, J.M., Rouse, D.J. and American College of Obstetricians and Gynecologists (2014) Safe Prevention of the primary Cesarean Delivery. American Journal of Obstetrics and Gynecology, 210, 179-193. https://doi.org/10.1016/j.ajog.2014.01.026

[7] The American College of Obstetricians and Gynecologists (2016) Refusal of Medically Recommended Treatment during Pregnancy.

http://www.acog.org/Resources-And-Publications/Committee-Opinions/Committe e-on-Ethics/Refusal-of-Medically-Recommended-Treatment-During-Pregnancy

[8] Miranda L., Dixon, V. and Reyes, C. (2015) How States Handle Drug Use during 
Pregnancy.

https://projects.propublica.org/graphics/maternity-drug-policies-by-state

[9] Kabbani, S.M.H. and Muhammad, S. (2016) Understanding Islamic Law. The Islamic Supreme Council of North America.

http://www.islamicsupremecouncil.org/understanding-islam/legal-rulings/52-under standing-islamic- law.html

[10] Understanding Islam (2017) The Four Schools of Law in Islam.

http://free-islamic-course.org/stageone/stageone-module-4/four-schools-law-islam. $\underline{\mathrm{html}}$

[11] Duweish, A.A. (2010) Fetal Rights in Islamic Law. DarEshbiliah for Publishing and Distribution, Riyadh, Saudi Arabia. (In Arabic)

[12] The Holy Quran (n.d.) Oxford World's Classics. Abdel Haleem, M.A.S., Trans., Oxford University Press, Oxford. 2008, Quran, 17: 33.

[13] Albelaihid, K.S. (2009) The Rule of the Surgery without the Patient's Permission. (In Arabic) https://saaid.net/Doat/binbulihed/f/233.htm

[14] Madhadji, M.H. (2010) Caesarean Rule Generation Operations. (In Arabic) http://dawnislam.blogspot.com/2012/09/blog-post_18.html

[15] Albar, M.A. (2001) Induced Abortion from an Islamic Perspective: Is It Criminal or Just Elective? Journal of Family and Community Medicine, 8, 25.

\section{Submit or recommend next manuscript to SCIRP and we will provide best} service for you:

Accepting pre-submission inquiries through Email, Facebook, LinkedIn, Twitter, etc. A wide selection of journals (inclusive of 9 subjects, more than 200 journals)

Providing 24-hour high-quality service

User-friendly online submission system

Fair and swift peer-review system

Efficient typesetting and proofreading procedure

Display of the result of downloads and visits, as well as the number of cited articles

Maximum dissemination of your research work

Submit your manuscript at: http://papersubmission.scirp.org/

Or contact ojog@scirp.org 